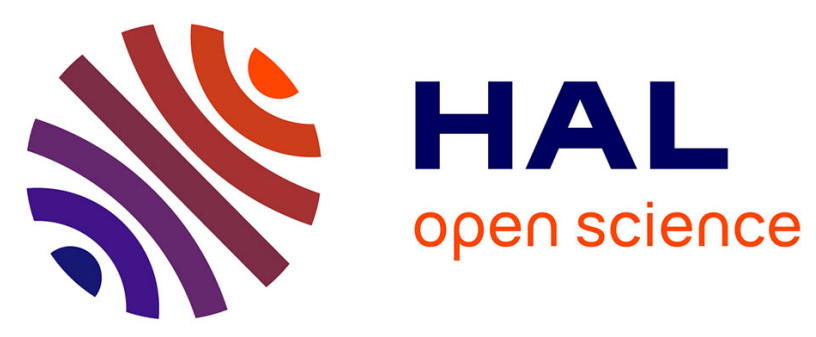

\title{
Soil moisture retrieval over irrigated grasslands using X-band SAR data combined with optical data acquired at high resolution
}

Mohammad El Hajj, N. Baghdadi, Mehrez Zribi, Gilles Belaud, B. Cheviron, Dominique Courault, F. Charron

\section{To cite this version:}

Mohammad El Hajj, N. Baghdadi, Mehrez Zribi, Gilles Belaud, B. Cheviron, et al.. Soil moisture retrieval over irrigated grasslands using X-band SAR data combined with optical data acquired at high resolution. IGARSS 2015, Jul 2015, Milan, France. pp.1328-1331, 10.1109/IGARSS.2015.7326020 . hal-01247210

\author{
HAL Id: hal-01247210 \\ https://hal.science/hal-01247210
}

Submitted on 21 Dec 2015

HAL is a multi-disciplinary open access archive for the deposit and dissemination of scientific research documents, whether they are published or not. The documents may come from teaching and research institutions in France or abroad, or from public or private research centers.
L'archive ouverte pluridisciplinaire HAL, est destinée au dépôt et à la diffusion de documents scientifiques de niveau recherche, publiés ou non, émanant des établissements d'enseignement et de recherche français ou étrangers, des laboratoires publics ou privés. 


\title{
SOIL MOISTURE RETRIEVAL OVER IRRIGATED GRASSLANDS USING X-BAND SAR DATA COMBINED WITH OPTICAL DATA ACQUIRED AT HIGH RESOLUTION
}

\author{
Mohammad El Hajj ${ }^{1}$, Nicolas Baghdadi ${ }^{2}$, Mehrez Zribi ${ }^{2}$, Gilles Belaud ${ }^{3}$, Bruno Cheviron ${ }^{4}$, \\ Dominique Courault ${ }^{5}$, François Charron ${ }^{3}$ \\ ${ }^{1}$ IRSTEA, UMR TETIS, 500 rue François Breton, 34093 Montpellier cedex 5, France \\ ${ }^{2}$ CESBIO (CNRS/IRD/UPS/CNES), 18 av. Edouard Belin, bpi 2801, 31401 Toulouse cedex 9, France \\ ${ }^{3}$ SupAgro, UMR G-EAU, 2 place Pierre Viala, 34060 Montpellier, France \\ ${ }^{4}$ IRSTEA, UMR G-EAU, 361 rue François Breton, 34196 Montpellier cedex 5, France \\ ${ }^{5}$ INRA, UMR 1114 EMMAH, Domaine St. Paul, 84914, Avignon, France
}

\begin{abstract}
The aim of this study was to develop an inversion approach to estimate surface soil moisture from $\mathrm{X}$ band SAR data over irrigated grassland areas. This approach is based on the coupling between Synthetic Aperture Radar and optical images through the Water Cloud Model.

An inversion technique based on multi-layer perceptron neural networks was used to invert the WCM for soil moisture estimation. Three inversion configurations were defined: (1) HH polarization, (2) $\mathrm{HV}$ polarization, and (3) both $\mathrm{HH}$ and $\mathrm{HV}$ polarizations, all including the Leaf Area Index derived from optical images. For the three inversion configurations, the NNs were trained and validated using a noisy synthetic dataset generated by the WCM for a wide range of soil moisture and LAI values. The trained NNs were then validated from a real dataset. The use of $\mathrm{X}$ band SAR measurements in $\mathrm{HH}$ polarization yields more precise results on soil moisture estimates.
\end{abstract}

Index Terms - Irrigated grassland, X-band Synthetic Aperture Radar, neural networks, inversion, soil moisture.

\section{INTRODUCTION}

Monitoring the spatio-temporal evolution of soil moisture over irrigated grassland areas is needed for appropriate and crop management [1]. The in situ sensors used for soil moisture measurements are costly, and provide only local information: they are not sufficient to monitor the spatial patterns of soil moisture over large irrigated grassland areas, expecting heterogeneities due to local climatic effects, lateral gradients of soil properties and imperfections in water application techniques. Thus, these sensors are not sufficient to monitor the soil moisture in large irrigated grassland areas, since the soil moisture presents large heterogeneities due to environmental characteristics and irrigation practices. SAR (Synthetic Aperture Radar) data have shown a great potential to provide spatially distributed surface soil moisture over bare and vegetated soil at huge scale (up to regional scale) with high spatial and temporal resolutions.

Over bare soil (or soil with little vegetation cover) the estimation of soil moisture was performed using either a physical or statistical model in an inversion scheme. The most commonly used physical model is the Integral Equation Model (IEM) developed by Fung et al. [2]. The IEM model simulates the backscattering coefficients using the radar configuration (frequency, polarization, and incidence angle) and soil parameters (soil moisture and roughness) as inputs. In addition, statistical models built using observed SAR data combined with ground-truthed measurements of soil moisture and roughness have often been used to map the soil moisture at regional scale. The most popular statistical models used to estimate soil moisture in inversion procedures are the Oh [3] and Dubois et al. [4] models. Most of the studies used radar data in the $\mathrm{X}$ and $\mathrm{C}$ bands to estimate the soil moisture of bare soil and have shown good results, with an accuracy 
between 3 and 6 Vol.\% (Volumetric unit expressed in percent) [5]-[7]. The presence of vegetation cover complicates soil moisture retrieval from SAR data because the water content of vegetation cover contributes to the total backscattered radar signal [8]. Therefore, over vegetated areas, the total backscattered radar signal is the result of contributions from the underlying soil and the vegetation. For these cases, most studies have used the Water Cloud Model (WCM) in an inversion scheme for soil moisture estimation; modelling total reflected radar signal as a function of the vegetation and soil contribution. The vegetation contribution (direct scattering and attenuation) is computed mainly using one biophysical parameter that account for the overall vegetation effect. This biophysical parameter could be estimated from optical data. Therefore, it is important to combine SAR and optical data for operational mapping of soil moisture over areas covered by vegetation [8], [9].

This work is part of the preparation for the coupled use of SENTINEL 1 and SENTINEL 2 data (radar and optical sensors, respectively). The aim of this study is to evaluate the potential of $\mathrm{X}$ band SAR data combined with optical data to estimate soil moisture over irrigated grassland areas located in southeastern France. An approach based on the inversion of the WCM using multi-layer neural networks (NNs) was developed. This approach relies on four main steps: (1) parameterize the WCM, (2) simulate learning the SAR synthetic dataset, (3) train the neural networks according to three inversion configurations using a part of the synthetic dataset, and finally (4) apply the trained NNs on synthetic and real datasets to validate the inversion approach. In this paper, section 2 presents the study area. Section 3 describes spatial images and the ground-truth measurements performed in situ. Section 4 describes the methodology. The results are shown in section 5. Finally, section 6 presents the principal conclusions.

\section{STUDY AREA AND IN SITU MEASURMENTS}

The study area, "Domaine de Merle", is an experimental farm located in southeastern French (centered at $43.64^{\circ} \mathrm{N}$ and $5^{\circ} \mathrm{E}$, Figure 1). Its extent is about 400 hectares, among which 150 hectares are irrigated grassland dedicated to hay production. Plots were leveled with very gentle slope to allow irrigation by gravity (border irrigation). Irrigation is applied by the overflow of ditches and canals which bring water "upstream" the plots. Each plot is irrigated on average each 10 days. Plots are harvested three times a year, in May, July and September.

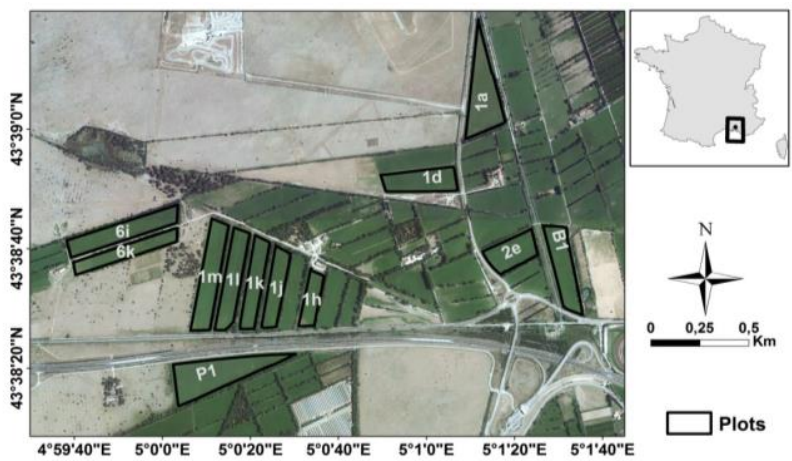

Figure 1: Location of study site (Domaine du Merle). Black polygons delineate training irrigated grassland plots.

\section{SAR DATA AND IN SITU MEASURMENTS}

Twenty three X-band SAR images were acquired by COSMO-SkyMed and TerraSAR-X sensors between April and October 2013. All SAR images are in dualpolarization mode ( $\mathrm{HH}$ and $\mathrm{HV}$ ) with incidence angles between $28.3^{\circ}$ and $32.5^{\circ}$. Radiometric calibration of the TSX and CSK images was performed using algorithms developed by the German Aerospace Center (DLR) and the Italian Space Agency (ASI), respectively.

Moreover, thirty optical images were acquired by SPOT-4/5, LANDSAT-7/8 between April and October 2013 at dates very close to SAR images. Optical images were corrected for atmospheric effects and ortho-rectified. Optical images were used to compute the Normalized Difference Vegetation Index (NDVI).

In situ measurements of soil moisture and the vegetation biophysical parameters (Leaf Area Index "LAI", biomass, crop height) were performed simultaneously with radar acquisitions on ten plots. The Leaf Area Index "LAI", Fraction of Absorbed Photosynthetically Active Radiation "FAPAR", and the Fractional vegetation COVER "FCOVER are estimated from hemispherical photographs processed by the Can-eye software developed by Weiss et al.[10].

\section{METHODS}

An inversion technique based on Multi-layer perceptron Neural Networks (NNs) was developed to 
invert WCM and estimate volumetric soil moisture (Mv). The WCM was in a first step parameterized using $47 \%$ of the real dataset $(53 \%$ were used in the validation process). In a second step, WCM is used to generate SAR synthetic dataset taking into account the LAI values (which can be computed from optical images) to represent the vegetation effect. In synthetic dataset, the simulated backscattering coefficients from the WCM were noised using absolute additive noise of $\pm 1 \mathrm{~dB}$ to make simulated backscattering coefficients closer to real SAR measurements. Moreover, a relative additive noise of $30 \%$ was added to the LAI values, to handle the uncertainty attached to LAI estimated from optical images. Three inversion configurations were defined, replying on the same vegetation parameter (here LAI) with different radar configuration: (1) radar signal in $\mathrm{HH}$ polarization, (2) radar signal in $\mathrm{HV}$ polarization, and (3) radar signal in both $\mathrm{HH}$ and $\mathrm{HV}$ polarizations. For each inversion configuration, the $\mathrm{NNs}$ were trained with the synthetic dataset, and applied to the real dataset of validation in order to validate the inversion approach.

\section{SOIL MOISTURE RETRIEVAL}

Statistics (RMSE: Root Mean Square Error and Bias) were computed on $\mathrm{Mv}$ from the real dataset of validation for LAI classes of $1 \mathrm{~m}^{2} / \mathrm{m}^{2}$ (LAI groundtruth measurements are between 0.1 and $6 \mathrm{~m}^{2} / \mathrm{m}^{2}$ ). Results on $\mathrm{Mv}$ estimates were presented for two classes of LAI: LAI lower and higher than $3 \mathrm{~m}^{2} / \mathrm{m}^{2}$ (Table 1: RMSE and bias, Figure 2: correlation between in situ and estimated $\mathrm{Mv}$ ).

RMSE of about 4.7, 6.6 and 5.4 Vol.\% were observed respectively for inversion configurations 1,2 and 3 in the case of LAI lower than $3 \mathrm{~m}^{2} / \mathrm{m}^{2}$. For LAI higher than $3 \mathrm{~m}^{2} / \mathrm{m}^{2}$, the RMSE on Mv estimates is about 7.5, 9.9 and 9.6 Vol. \% respectively for configurations 1, 2 and 3. Thus the RMSE on Mv estimates is lower for LAI $<3 \mathrm{~m}^{2} / \mathrm{m}^{2}$. Moreover, results showed that for LAI $<3 \mathrm{~m}^{2} / \mathrm{m}^{2}$ the trained NNs provide Mv estimates with slight bias (estimated Mv reference $\mathrm{Mv}$ ) in configurations $1(0.7 \mathrm{Vol} . \%)$ and 2 ($1.0 \mathrm{Vol} . \%$ ), and zero bias in configuration 3. For LAI $>3 \mathrm{~m}^{2} / \mathrm{m}^{2}$, an underestimation of $\mathrm{Mv}$ ranges between 3.2 and $-0.4 \mathrm{Vol} . \%$ was observed, with the lower value for the inversion using $\mathrm{HH}$ and LAI (-0.4 Vol.\%).

\begin{tabular}{|c|c|c|}
\hline & $\mathbf{L A I}<\mathbf{3} \mathbf{~ m}^{\mathbf{2}} / \mathbf{m}^{\mathbf{2}}$ & $\mathbf{L A I}>\mathbf{3} \mathbf{~ m}^{\mathbf{2}} \mathbf{~ m}^{\mathbf{2}}$ \\
\hline $\begin{array}{c}\text { Configuration 1 } \\
\text { (HH and LAI) }\end{array}$ & $4.7 / 0.7$ & $7.5 /-0.4$ \\
\hline $\begin{array}{c}\text { Configuration 2 } \\
\text { (HVand LAI) }\end{array}$ & $6.6 /-1.0$ & $9.9 /-3.2$ \\
\hline $\begin{array}{c}\text { Configuration 3 } \\
\text { (HH, HVand LAI) }\end{array}$ & $5.4 / 0.0$ & $9.6 /-3.0$ \\
\hline
\end{tabular}

Table 1. RMSE and Bias on $M_{v}$ estimates according to the three inversion configurations (RMSE/Bias in Vol.\%).

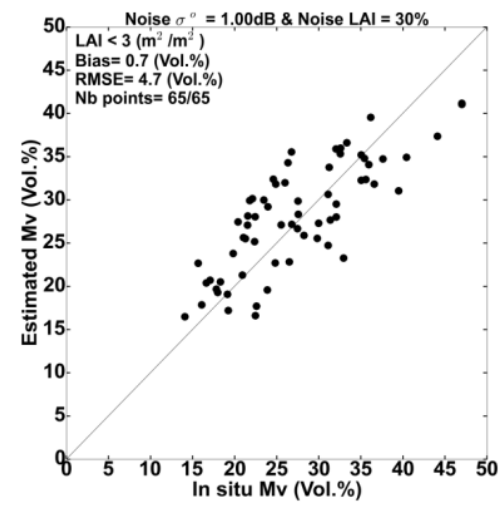

(a)

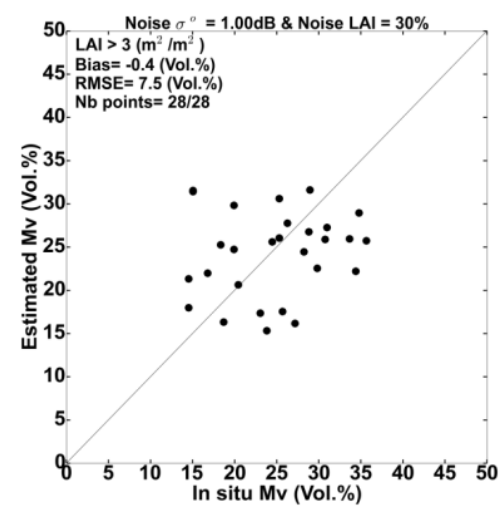

(b)

Figure 2: Retrieved $\mathrm{M}_{\mathrm{v}}$ with configuration 1 (HH and LAI) versus in situ measurements for LAI in situ lower than 3 $\mathrm{m}^{2} / \mathrm{m}^{2}(\mathrm{a})$, and higher than $3 \mathrm{~m}^{2} / \mathrm{m}^{2}(\mathrm{~b})$.

\section{CONCLUSIONS}

From the real validation dataset $(53 \%$ of the real dataset), the soil moisture estimation using the $\mathrm{X}$ band SAR (in addition to LAI: configuration 1) allows better results with $\mathrm{HH}$ polarization than with $\mathrm{HV}$ or both $\mathrm{HH}$ and HV. With $\mathrm{HH}$ and LAI information derived from optical images, the accuracy on the soil moisture estimation was $4.7 \mathrm{Vol} . \%$ for LAI between 0 and $3 \mathrm{~m}^{2} / \mathrm{m}^{2}$ and $7.5 \mathrm{Vol} . \%$ when the LAI of the grassland was between 3 and $6 \mathrm{~m}^{2} / \mathrm{m}^{2}$. With the arrival 
of Sentinel-1 ( $C$ band), the estimation of $M_{v}$ will be more precise because the penetration depth of the radar into the vegetation cover is higher in the $\mathrm{C}$ band than in the $\mathrm{X}$ band.

This study demonstrated that the use of NNs technique to invert $\mathrm{X}$ band SAR backscattering coefficients allows the estimation of soil moisture with acceptable accuracy (RMSE of 4.7 Vol.\% for a LAI lower than $3 \mathrm{~m}^{2} / \mathrm{m}^{2}$ ). Current remote sensing sensors (optical and SAR) and those available in the near future (spatial resolution better than $10 \mathrm{~m}$ ) will allow the estimation of soil moisture at a field scale with high temporal resolution (better than weekly).

\section{ACKNOWLEDGEMENTS}

This research was supported by the French Space Study Center (CNES, DAR 2015 TOSCA) and the Islamic Development Bank (PhD Scholarship of $\mathrm{M}$. Mohammad El Hajj). Field experiments were carried out within the SicMed-Crau program. The CSK images used in this analysis were supported by public funds received in the GEOSUD framework, a project (ANR-10-EQPX-20) of the "Investissements d'Avenir" program managed by the French National Research Agency. The authors wish to thank the German Space Agency (DLR) for kindly providing the TSX images under proposal HYD0007. We also wish to thank the EMMAH unit (INRA) for providing meteorological data and the technical teams of ASI and DLR for providing answers regarding the performances of CSK and TSX. Finally, we would like to thank Olivier Hagolle (CNES-CESBIO: Centre National d'Etudes Spatiales-Centre d'Etudes Spatiales de la BIOsphère) for providing calibrated SPOT 4 images in the framework of Take 5 experiments.

\section{REFERENCES}

[1] R. P. O. Schulte, J. Diamond, K. Finkele, N. M. Holden, and A. J. Brereton, "Predicting the soil moisture conditions of Irish grasslands," Ir. J. Agric. Food Res., pp. 95-110, 2005.

[2] A. K. Fung, Z. Li, and K. S. Chen, "Backscattering from a randomly rough dielectric surface," Geosci. Remote Sens. IEEE Trans. On, vol. 30, no. 2, pp. 356-369, Mar. 1992.

[3] Y. Oh, "Quantitative retrieval of soil moisture content and surface roughness from multipolarized radar observations of bare soil surfaces," Geosci. Remote Sens. IEEE Trans. On, vol. 42, no. 3, pp. 596601, 2004.

[4] P. C. Dubois, J. Van Zyl, and T. Engman, "Measuring soil moisture with imaging radars," Geosci. Remote Sens. IEEE Trans. On, vol. 33, no. 4, pp. 915-926, 1995.

[5] M. Aubert, N. Baghdadi, M. Zribi, A. Douaoui, C. Loumagne, F. Baup, M. El Hajj, and S. Garrigues, "Analysis of TerraSAR-X data sensitivity to bare soil moisture, roughness, composition and soil crust," Remote Sens. Environ., vol. 115, no. 8, pp. 18011810, 2011.

[6] N. Baghdadi, R. Cresson, M. El Hajj, R. Ludwig, and I. La Jeunesse, "Estimation of soil parameters over bare agriculture areas from C-band polarimetric SAR data using neural networks.," Hydrol. Earth Syst. Sci., vol. 16, no. 6, pp. 1607-1621, 2012.

[7] M. Zribi, N. Baghdadi, N. Holah, and O. Fafin, "New methodology for soil surface moisture estimation and its application to ENVISAT-ASAR multi-incidence data inversion," Remote Sens. Environ., vol. 96, no. 3, pp. 485-496, 2005.

[8] B. He, M. Xing, and X. Bai, "A Synergistic Methodology for Soil Moisture Estimation in an Alpine Prairie Using Radar and Optical Satellite Data," Remote Sens., vol. 6, no. 11, pp. 10966-10985, 2014.

[9] R. Fieuzal, B. Duchemin, L. Jarlan, M. Zribi, F. Baup, O. Merlin, O. Hagolle, and J. Garatuza-Payan, "Combined use of optical and radar satellite data for the monitoring of irrigation and soil moisture of wheat crops.," Hydrol. Earth Syst. Sci., vol. 15, no. 4, pp. 1117-1129, 2011.

[10] M. Weiss, F. Baret, G. J. Smith, I. Jonckheere, and P. Coppin, "Review of methods for in situ leaf area index (LAI) determination: Part II. Estimation of LAI, errors and sampling," Agric. For. Meteorol., vol. 121, no. 1, pp. 37-53, 2004. 